\title{
Políticas públicas e territoriais em perspectiva: a política para além da gestão
}

Floriano José Godinho de Oliveira e Guilherme Ribeiro

\section{(2) OpenEdition \\ 1 Journals}

\section{Edição electrónica}

URL: http://journals.openedition.org/espacoeconomia/599

DOI: 10.4000/espacoeconomia.599

ISSN: 2317-7837

Editora

Núcleo de Pesquisa Espaço \& Economia

\section{Refêrencia eletrónica}

Floriano José Godinho de Oliveira e Guilherme Ribeiro, « Políticas públicas e territoriais em perspectiva: a política para além da gestão », Espaço e Economia [Online], 3 | 2013, posto online no dia 13 dezembro 2013, consultado o 22 setembro 2020. URL : http://journals.openedition.org/ espacoeconomia/599; DOI : https://doi.org/10.4000/espacoeconomia.599

Este documento foi criado de forma automática no dia 22 setembro 2020.

(C) NUPEE 


\title{
Políticas públicas e territoriais em perspectiva: a política para além da gestão
}

\author{
Floriano José Godinho de Oliveira e Guilherme Ribeiro
}

1 A manifestação popular do dia 20 de junho de 2013 na cidade do Rio de Janeiro, que reuniu 1 milhão e 200 mil pessoas e culminou com uma forte repressão por parte das forças de segurança para dispersar os manifestantes, demonstrou que o povo não admite - e deu demonstrações de sua capacidade política de enfrentamento - dois fenômenos presentes na administração pública brasileira: a rejeição, por parte dos membros dos poderes Executivo, Legislativo e Judiciário, de maior participação popular no delineamento das políticas públicas; e, mais grave ainda, a subordinação das políticas urbanas e de ordenamento do território fluminense às determinações do mercado imobiliário, como fica evidente na preparação da cidade para os megaeventos esportivos. O primeiro aspecto pode ser constatado pela identificação da principal bandeira de luta daquela manifestação: a redução dos preços das passagens de ônibus, cujo aumento previsto para vigorar a partir de $1^{\circ}$ de junho foi revogado por força das manifestações. $O$ segundo aspecto se evidencia nas tensões implicadas com a atuação do governo do estado na organização da Copa das Confederações. Como no mesmo dia do ato público ocorria um dos jogos da Copa (Espanha vs. Taiti), o governo do estado decretou feriado a partir das 14:00 horas na expectativa de esvaziar a cidade e, por conseguinte, o próprio ato. $\mathrm{O}$ efeito obtido, no entanto, foi exatamente o contrário: a cidade encheu-se de cores, de pessoas e de espírito de contestação a tudo o que vem ocorrendo no Rio de Janeiro e no Brasil.

Quanto à preparação da cidade para os megaeventos, cabe observar que, ao contrário das expectativas difundidas pelo governo referente à construção de uma infraestrutura que deixará um legado social para a cidade do Rio de Janeiro, o que vemos de fato é que todos os investimentos estão sendo estruturados com base em um movimento profundamente especulativo e de uso instrumental do território - portanto, sem nenhuma perspectiva que promova qualquer desenvolvimento social. Trata-se de um 
processo que valoriza o capital corporativo e especulativo (tal como o aplicado no setor imobiliário), cuja resultante previsível está totalmente descolada do que seria de interesse da população.

3 A esse respeito é importante a crítica produzida por David Harvey, para quem

[...] é possível elaborar uma perspectiva crítica sobre a versão contemporânea do empreendedorismo urbano. Em primeiro lugar, a análise deve enfocar o contraste entre o vigor superficial de diversos projetos de regeneração de economias urbanas debilitadas e as tendências subjacentes da condição urbana. Deve-se reconhecer que, sob a camuflagem de muitos projetos de sucesso, existem alguns problemas sociais e econômicos muito sérios, e que isso, em muitas cidades, está assumindo um caráter geográfico, na forma de uma cidade dupla, com a regeneração de um centro decadente e um mar circundante de pobreza crescente (Harvey, 2005: 186 [1989]).

4 Ao apresentarmos esta edição da revista Espaço e Economia, fazemos questão de registrar esse importante fato político para o Rio de Janeiro, pois a maior parte dos artigos aqui publicados está relacionada à execução de políticas públicas e ações que produziram ou estão produzindo mudanças nas práticas sócio-espaciais e, consequentemente, propondo novas políticas territoriais. Assim, não poderíamos deixar de enfatizar que uma análise correta dos fenômenos sociais inscritos nesta conjuntura política deve estar ancorada conceitualmente no que estamos denominando política territorial. Neste sentido, resgatamos a interpretação de Sanchez i Peres, que sublinha a relação entre política e território ressaltando que território e política formam um par dialético indissociável. Para o autor, deve-se destacar

[...] o fato de que, se, por um lado, as forças políticas dirigem a organização e o ordenamento do território, por outro o território influencia diretamente na política de gestão desse espaço social. Portanto, estamos tratando da relação entre política e território, e consideramos que a base territorial é condição necessária para a existência de toda organização política (Sànchez i Peres, 1991:33-34. Ver também Sánchez, 1991).

5 Esta formulação contribui para a superação da noção de que o território restringe-se ao espaço delimitado de um determinado poder, poder político que domina e regula o território, que grava no mesmo determinadas relações e sobre o qual exerce, supostamente com exclusividade, a prerrogativa de livre disposição sobre seu uso. Outra contribuição acerca da necessidade de superarmos a limitação desta abordagem é feita por Milton Santos, quando identifica o quanto precisamos avançar politicamente na compreensão do território, revendo as bases do conceito e superando a concepção que afirma o território unificado normativamente como expressão unívoca do exercício de um poder.

Vivemos com uma noção de território herdada da Modernidade incompleta e do seu legado de conceitos puros, tantas vezes atravessando os séculos praticamente intocados. É o uso do território, e não o território em si mesmo, que faz dele objeto da análise social. (...) Hoje, quando vivemos uma dialética do mundo concreto, evoluímos da noção, tornada antiga, de Estado Territorial para a noção pósmoderna de transnacionalização do território (Santos, 2005:15 [1994]).

6 Na contemporaneidade, devemos pensar o território como uma totalidade que expressa muito mais que a delimitação territorial do poder político formal. Concretamente, o território possibilita desvelar as contradições e as tensões sociais que caracterizam os distintos interesses de capitalistas e trabalhadores em uma economia de mercado. Ou seja, trabalhamos com a perspectiva de focar conflitos, pois, ao refletirmos sobre as relações de poder que organizam o território, estamos pensando nas múltiplas e 
intensas possibilidades abertas pela vida social que, como nos ensina Henri Lefebvre, constituem o processo por meio do qual se produz e se reproduz espaço social (Lefebvre, 1980, 1978, 1976, 1971). Por isso, propomos não nos atermos somente à análise das intervenções do capital corporativo e do Estado na promoção de ações que modificam as formas de organização do território mas, para além disto, pensar também as possibilidades de uso de seus recursos a partir das disputas que delineiam tal organização.

7 Isto posto, esperamos que a leitura dos textos aqui presentes contribua para ampliar nossa capacidade de crítica às perspectivas circunscritas à mera gestão do território, projetando-nos ao debate das políticas territoriais em seu sentido pleno. De acordo com nossa linha editorial, os primeiros artigos focarão temas e questões mais gerais, no plano teórico e histórico, da Geografia como Ciência Social - que, em grande medida, prepara-se, cada vez mais, para assumir "projeção aplicada", conforme sugere Fernando Manero (editor da Revista Polígonos, Universidade de Valladolid, Espanha [http://revpubli.unileon.es/ojs/index.php/poligonos/index]). Em seguida, apresentamos vários artigos que focarão políticas públicas de caráter regional, enfatizando linhas de financiamento, logísticas produtivas e intervenções econômicas no Rio de Janeiro.

80 artigo que abre o número terceiro da Espaço e Economia recupera importante e perspicaz abordagem sobre os fundamentos da geografia econômica à luz de um dos principais geógrafos da cena atual: o britânico radicado nos Estados Unidos David Harvey. Assinado por Paul Claval (Universidade de Paris-Sorbonne), Marxismo e geografia econômica na obra de David Harvey - conferência de abertura do II Seminário Espaço e Economia: Políticas Territoriais, Intervenção do Estado e Práticas Sociais na Reestruturação do Espaço, organizado pelo NUPEE em 2011 - é o diálogo de um dos maiores pesquisadores da história do pensamento geográfico com aquele que vem propondo repensar o marxismo a partir das características assumidas pelo modo de produção capitalista desde a segunda metade do século XX. Reconhecendo tanto os avanços perpetrados por Harvey quanto o que considera limites do marxismo, Claval continua a tensionar - tal como vem fazendo desde os anos setenta (Claval, 1977, 1985, 1987) - os analistas desta corrente de pensamento de maneira transparente e respeitosa: ao mesmo tempo que considera incontornável a interlocução com o marxismo, também faz questão de identificar suas ressalvas diante do mesmo. Se Claval não está de acordo com Harvey no que diz respeito à própria natureza epistemológica do materialismo histórico, nem por isso deixa de reconhecer os sucessos de Harvey acerca do papel central das ideologias urbanas na reprodução do capitalismo (Claval, 2013).

9 A seguir, um dos principais pesquisadores da obra de Élisée Reclus (1830-1905), o geógrafo italiano Federico Ferretti (Universidade de Genebra) assina "Eles têm o direito de expulsar-nos": a Nova Geografia Universal de Élisée Reclus. Baseado em amplo levantamento bibliográfico e documental, Ferretti mostra a dimensão avant-garde da reflexão política de Reclus em pleno século XIX: um dos fundadores do movimento anarquista internacional, Reclus opõe-se de forma categórica ao imperialismo, ao racismo e ao eurocentrismo, renunciando todo e qualquer discurso que situasse o homem branco e europeu em esquemas hierárquicos de explicação da sociedade e da história. Além de revelar a notória atualidade da abordagem reclusiana aproximando-a, inclusive, de alguns elementos presentes na teoria pós-colonial -, Ferretti desmistifica a ideia de que era praticamente impossível um intelectual europeu 
do século XIX não aderir ao imperialismo e ao capitalismo. Seu texto também fornece inúmeros elementos para repensarmos as maneiras pelas quais a história do pensamento geográfico vem sendo narrada, além de sugerir nas entrelinhas algumas interessantes pistas de pesquisa a respeito das formulações de Reclus (Ferretti, 2013 [2012]).

10 Escritos respectivamente por Carla Hirt (estudante de doutorado do IPPUR) e Silvana Cristina da Silva (UFF), os artigos seguintes enfatizam políticas de financiamento e de planejamento na escala regional latino-americana e aspectos gerais no plano da economia regional. $\mathrm{O}$ primeiro objetiva problematizar as políticas de desenvolvimento financiadas e/ou realizadas por meio de parcerias entre o setor privado e o Banco Nacional de Desenvolvimento Econômico e Social (BNDES), bem como os desdobramentos territoriais de empreendimentos realizados no âmbito da Iniciativa para a Integração da Infraestrutura Regional Sul-Americana (IIRSA) como propulsora do desenvolvimento sul-americano. Em O papel do BNDES nas políticas de desenvolvimento e integração regional, a autora destaca que muitos desses projetos têm sido duramente questionados por inúmeros sujeitos que declaram que tais obras de infraestrutura, da maneira como foram planejadas, darão continuidade ao processo de espoliação sofrido durante anos pelo continente sul-americano, tendo em vista o impacto territorial local e os sujeitos que serão beneficiados durante a execução e após a conclusão das obras (Hirt, 2013). Por sua vez, A regionalização do circuito espacial de produção do vestuário no Brasil promove uma análise sobre o processo de reorganização do circuito espacial de produção do vestuário no Brasil no período atual. Destaca a desconcentração da etapa de produção e a centralização do capital das empresas que comandam os circuitos de acumulação, bem como, a partir desta reestruturação produtiva, a ampliação das formas de subcontratação de pessoal e dos modos como tais processos vêm aprofundando a divisão técnica e territorial do trabalho - cabendo às grandes empresas (compostas por grandes varejistas e marcas) a execução das etapas de pesquisa, concepção, design, logística e marketing, enquanto às pequenas oficinas é reservada a execução da costura. Em termos metodológicos, Silva destaca a inserção das grandes empresas no circuito superior da economia e das oficinas no circuito inferior (Silva, 2013).

$11 \mathrm{Na}$ sequência, os quatro trabalhos apresentados constituem importantes esforços visando apreender as mudanças decorrentes do dinamismo econômico no estado do Rio de Janeiro. Eletrificação e formação do patrimônio territorial da Light na cidade do Rio de Janeiro e no Médio Vale do Paraíba, de Floriano José Godinho de Oliveira (PPFH/UERJ) expõe breve resgate analítico da contribuição das redes técnicas no desenvolvimento urbano e industrial da cidade do Rio de Janeiro, com forte influência no delineamento de uma base territorial urbana e rural da empresa em tela, que se baseou na produção de um sistema monopolístico de produção e distribuição de energia. A partir da formação dessa estrutura de serviços e de equipamentos públicos, o autor mostra a influência da Light na organização dos serviços de transportes e no impulsionamento do forte caráter especulativo da terra urbana na cidade do Rio de Janeiro (Oliveira, 2013).

Os textos de Regina Celi Pereira, Estado, território e reestruturação produtiva na metrópole fluminense, e de Letícia Giannella, A produção histórica do espaço portuário da cidade do Rio de Janeiro e o projeto Porto maravilha: correspondência entre os grandes ciclos de acumulação capitalista e as morfologias urbanas, oferecem uma leitura mais contemporânea das 
mudanças no território do estado do Rio de Janeiro, tanto em termos dos novos padrões espaciais das estruturas produtivas e seus efeitos na reconfiguração da metrópole fluminense quanto das mudanças do padrão de uso da zona central da cidade. Pereira identifica um movimento de reconcentração da base econômica no espaço metropolitano do Rio de Janeiro, já que há um conjunto significativo de empreendimentos que redefinem o papel da metrópole no conjunto da economia do estado. Ela procura reconhecer planos e processos que estão nas bases da dinâmica territorial vinculada à reestruturação econômica, restruturação esta que reafirmou o papel de comando da Região Metropolitana do Rio de Janeiro (Pereira, 2013). A seu turno, Giannella examina o espaço portuário da cidade do Rio de Janeiro e o processo histórico de sua formação. Para tanto, ela lança mão da correspondência entre os ciclos seculares de acumulação capitalista analisados por Giovanni Arrighi (mercantilismo, liberalismo, fordismo/keynesianismo e neoliberalismo) e as morfologias urbanas visualizadas na área. 0 que a autora sustenta é que tal espaço caracteriza-se por ter sido historicamente produzido sem que tenha havido, da parte dos agentes hegemônicos, qualquer olhar para as áreas ocupadas pelas populações que ali vivem e viveram. Tal prática parece repetir-se no decorrer da elaboração e da implementação do Projeto Porto Maravilha (Gianella, 2013).

13 Sinalizando nossa clara intenção de conversar com a América que fala e pensa em castelhano, é com alegria que Espaço e Economia decidiu incluir os resumos de seus artigos também neste idioma, além de acolher seu primeiro trabalho escrito na língua de nossos vizinhos. Trata-se de Aglomeraciones residenciales de negros libres en Río de Janeiro (Brasil) y en Richmond (Virginia, Estados Unidos) a mediados del siglo XIX, do historiador colombiano Carlos Eduardo Valencia Villa (UFF). Sua investigação mostra como o approach quantitativo é valorizado quando articulado à dimensão espacial. É bastante frutífera a abordagem comparativa entre as cidades Rio de Janeiro e Richmond. Trata-se de pesquisa que ensina os geógrafos a não negligenciarem a escravatura e a abolição no final do século XIX como elementos-chave no processo histórico de ocupação espacial da cidade do Rio de Janeiro. Negros livres se dispersavam pela cidade? Isto nos diz algo sobre o presente, é claro, e os mapas elaborados por Villa com base em fontes censitárias serão assaz elucidativos para a geografia urbana atual (Villa, 2013). Afinal, como bem sabem os historiadores, o passado está longe de ser o passado, mas sim uma janela permanentemente aberta à disposição das inquietações do presente. No momento em que o legado dos escravos africanos tem sido sublinhado entre nós graças às recentes descobertas arqueológicas durante a operação de renovação da zona portuária, o artigo em tela em muito enriquece as relações geografia-história, espaço-tempo, presente-passado.

Destacamos ainda a importante reflexão dos pesquisadores Rosângela Viana Vieira (UFG) e Fábio Marvulle Bueno (UnB) em Capital fictício e urbanização ou Dos diversos usos do território. Eles discutem a necessidade teórica da compreensão do arranjo do território, especificamente o território urbano, nas condições capitalistas atuais onde a forma fictícia do capital ganha relevância. Na cidade, o processo de urbanização do seu território tanto produz uma expectativa de valorização para diversas frações do capital como sofre influência em sua organização pela presença das mesmas, especialmente a forma acima mencionada. $O$ entendimento da teoria marxiana do valor ressignifica o modo de pensar as coisas do mundo no espaço e, por conseguinte, o modo de refletir geograficamente. Ressignifica porque persiste(m) o(s) desconhecimento(s) tanto do processo intrínseco ao capitalismo quanto das formas e dos conteúdos 
inerentes às variadas territorialidades concernentes aos movimentos e nos movimentos que constituem a vida. As interações específicas entre a forma fictícia do capital e o uso do território urbano estabelecem metodologicamente a argumentação, especialmente em relação à maneira como as políticas urbanas são influenciadas pelo capital fictício na organização do espaço das cidades. Aos gestores urbanos é dada a incumbência de tornar as cidades atraentes aos fluxos de capital, de criar "chamarizes" para o capital fictício, o que implica uma infraestrutura específica para os grandes negócios financeiros (Vieira \& Bueno, 2013).

Encerra esta edição a resenha Um olhar liberal sobre a América Latina. Redigida por Lara D'Assunção dos Santos (formanda do curso de graduação em Geografia da UFRRJ) sobre o livro $O$ continente esquecido: a batalha pela alma latino-americana, de Michel Reid, trata-se de leitura liberal ao redor da história da América Latina na segunda metade do século XX. Retomando autores consagrados como Eduardo Galeano, Raul Prébisch, Fernando Henrique Cardoso e Enzo Faletto, a interlocução de Santos com Reid enfatiza os aspectos político-econômicos do continente e seus dilemas na consolidação de estruturas e instituições democráticas baseadas na economia de mercado (Santos, 2013).

Desejamos a todos uma boa leitura, bem como agradecemos o interesse que nosso periódico vem atraindo junto à comunidade geográfica nacional e aos mais variados países como Holanda, Alemanha, Bélgica, Rússia, Estados Unidos e Moçambique.

\section{BIBLIOGRAFIA}

CLAVAL, Paul. Marxismo e geografia econômica na obra de David Harvey. Espaço e Economia. Revista Brasileira de Geografia Econômica, ano II, n.3 (2013).

-_-_. Le néo-marxisme et l'espace, L'Espace Géographique, vol. 16, n. 3 (1987).

--- C Chronique de géographie économique n. $18:$ une nouvelle vague de modèles marxistes du monde contemporain. Revue Géographique de l'Est, vol. 25, n. 2-3 (1985).

-_-_. Le marxisme et l'espace. L'Espace géographique, vol. 6, n. 3 (1977).

FERRETTI, Federico. "Eles têm o direito de expulsar-nos": a Nova Geografia Universal de Élisée Reclus. Espaço e Economia. Revista Brasileira de Geografia Econômica, ano II, n.3 (2013 [2012]).

GIANELLA, Letícia. A produção histórica do espaço portuário da cidade do Rio de Janeiro e o projeto Porto maravilha: correspondência entre os grandes ciclos de acumulação capitalista e as morfologias urbanas. Espaço e Economia. Revista Brasileira de Geografia Econômica, ano II, n.3 (2013).

HARVEY, David. Do administrativismo ao empreendedorismo: a transformação da governança urbana no capitalismo tardio. In: HARVEY, David. A produção capitalista do espaço. São Paulo: Annablume (2005 [1989]).

HIRT, Carla. O papel do BNDES nas políticas de desenvolvimento e integração regional. Espaço e Economia. Revista Brasileira de Geografia Econômica, ano II, n.3 (2013). 
LEFEBVRE, Henri. Une pensée devenue monde. Faut-il abandonner Marx? Paris, Fayard (1980).

. El Derecho a la ciudad. Barcelona, Ediciones Península (1978).

. Espacio y política. El derecho a La ciudad II. Barcelona, ediciones península (1976).

. L'idéologie structuraliste. Paris, Éditions Anthropos (1971).

OLIVEIRA, Floriano José Godinho de. Eletrificação e formação do patrimônio territorial da Light na cidade do Rio de Janeiro e no Médio Vale do Paraíba. Espaço e Economia. Revista Brasileira de Geografia Econômica, ano II, n.3 (2013).

PEREIRA, Regina Celi. Estado, território e reestruturação produtiva na metrópole fluminense. Espaço e Economia. Revista Brasileira de Geografia Econômica, ano II, n.3 (2013).

SANTOS, Milton. O retorno do território. OSAL : Observatorio Social de América Latina, Buenos Aires, año 6, n. 16, jun. (2005 [1994]). Disponível em: http://bibliotecavirtual.clacso.org.ar/ar/libros/ osal/osal16/D16Santos.pdf.

SANTOS, Lara d'Assunção dos. Um olhar liberal sobre a América Latina (Resenha). Espaço e Economia. Revista Brasileira de Geografia Econômica, ano II, n.3 (2013).

SÁNCHEZ, Joan-Eugeni. Espacio, Economia y Sociedad. Barcelona: Siglo XXI de España (1991).

SÀNCHEZ i PÉREZ, Joan-Eugeni. La política i l'administraçió del territori. Institut D’Estudis Catalans, Primer Congrés Català de Geografia, II ponències. Barcelona (1991).

SILVA, Silvana Cristina da. A regionalização do circuito espacial de produção do vestuário no Brasil. Espaço e Economia. Revista Brasileira de Geografia Econômica, ano II, n.3 (2013).

VIEIRA, Rosângela Viana, BUENO, Fábio Marvulle. Capital fictício e urbanização ou Dos diversos usos do território. Espaço e Economia. Revista Brasileira de Geografia Econômica, ano II, n.3 (2013).

VILLA, Carlos Eduardo Valencia. Aglomeraciones residenciales de negros libres en Río de Janeiro (Brasil) y en Richmond (Virginia, Estados Unidos) a mediados del siglo XIX. Espaço e Economia. Revista Brasileira de Geografia Econômica, ano II, n.3 (2013).

\section{AUTORES}

\section{FLORIANO JOSÉ GODINHO DE OLIVEIRA}

Doutor em Geografia Humana pela USP, com pós-doutorado na Universidade de Barcelona, UB. Professor do Programa de Pós-Graduação em Políticas Públicas e Formação Humana (PPFH/UERJ) e do Programa de Pós-graduação em Geografia (PPGEO/FFP/UERJ). Email:fgodinho@uerj.br

\section{GUILHERME RIBEIRO}

Doutor em Geografia pela Universidade Federal Fluminense, com doutorado sandwich pela Universidade de Paris - Sorbonne (Paris IV). Pós-Doutor em Geografia pela Universidade Federal de Minas Gerais. Professor Adjunto do Depto. de Geociências da Universidade Federal Rural do Rio de Janeiro. E-mail: geofilos@ig.com.br 